\title{
Influence of Coal Bottom Ash on Properties of Portland cement Mortar
}

\section{Ali Huddin Ibrahim,", Choong Kok Keong', Megat Azmi Megat Johari', Mohamad Rohaidzat Mohamed Rashid ${ }^{2}$, Kamar Shah Ariffin ${ }^{2}$}

\author{
${ }^{1}$ School of Civil Engineering, Engineering Campus, \\ Universiti Sains Malaysia, 14300 Penang, MALAYSIA \\ ${ }^{2}$ School of Materials and Mineral Resources Engineering, Engineering Campus, \\ Universiti Sains Malaysia, 14300 Penang, MALAYSIA \\ *Corresponding Author
}

DOI: https://doi.org/10.30880/ijie.2019.11.01.008

Received 13 May 2018; Accepted 10 August 2018; Available online 05 May 2019

\begin{abstract}
In this study, the effects of coal bottom ash (CBA) on the properties of Portland cement mortar were investigated. Mortars with different proportions (cement: sand ratios) of 1:2.5 and 1:2.75 were prepared where the CBA was used to partially substitute the Portland cement. The influence of the CBA inclusion on the properties of the mortars, namely flow, compressive strength, porosity, water absorption and gas permeability was evaluated and compared with the reference mortar mixtures. The results showed that the use of CBA as partial Portland cement replacement material had clear influences on the investigated properties of the mortars. The use of CBA reduced the measured flow values of the fresh mortars, with higher reduction at higher CBA content. The effect of the CBA inclusion at 10 and $20 \%$ for the 1:2.5 mortar mixture and at $10 \%$ for the 1:2.75 mortar mixture increased the strength, but reduced the porosity, water absorption and permeability at longer curing periods of 28,56 and 90 days. The overall results of the study portray that the CBA has the potential to be used to partially replace Portland cement in the production of mortar and concrete.
\end{abstract}

Keywords: Coal bottom ash, compressive strength, porosity, water absorption, gas permeability

\section{Introduction}

Coal bottom ash is a non-combustible solid waste residue mainly generated from the coal-fired electricity generating power plants. In Malaysia, the production of coal bottom ash and fly ash from coal-fired power plant has tremendously increased. Abubakar and Baharudin [1] reported that Sejingkat Coal Fired Power Station at Kuching Sarawak deposited off both bottom ash and fly ash into an $81,000 \mathrm{~m} 2$ area and $2.4 \mathrm{~m}$ deep ash pond located besides the power station. Moreover, there are two ash ponds, one of which is fully utilized [2]. Muhardi et al. [3] also reported that, other power plants such as Tanjung Bin power station produce 1,620 tonnes per day of fly ash and 180 tonnes per day of bottom ash from 18,000 tonnes per day of coal burning alone.

The construction of many coal-fired power plants such as in Kapar, Manjung, Sejingkat, Jimah and Tanjung Bin has given a major impact on the environment resulting from the increased production of coal bottom ash. Generally, coal bottom ash is disposed or utilized as landfill or as base material in road construction. The limited availability of space for disposal of coal bottom ash is the main issue faced by the industry and some of the methods of disposal have their disadvantages which can lead to the contamination of natural ground water [1]. In order to minimize the disposal space and environmental impact, it has become a practice to reuse the coal bottom ash as part of cementitious materials in concrete industry. Several studies have been carried out to resolve the problem and explore any other potential use of 
coal bottom ash in the industry such as the study by Manz [4] which reported that bottom ash can be used as a partial or total fine aggregate replacement for natural sand. A study by Cheriaf et al. [5] identified that coal bottom ash with adequate grinding, can be used as a partial cement replacement material in Portland cement concrete production. In addition, studies of utilizing coal bottom ash as a construction material are continuously being done to maximize the potential use of coal bottom ash and at the same time minimize the environmental impact from this waste material [6]. However, a systematic investigation on some of the effects of coal bottom ash on the properties of mortar is still lacking especially in relation to the coal bottom ash from local power plants in Malaysia. Therefore, this study attempts to quantify the effects of utilizing treated coal bottom ash on the properties of Portland cement mortar both in the fresh and hardened states. The properties investigated include flow, compressive strength, porosity, water absorption and permeability. This study is important as there is strong possibility that the coal bottom ash can be used as part of the cementitious materials whilst resolving some of the related environmental issues towards achieving better sustainability.

\section{Materials and Methods}

The materials used in this study for the preparation of the Portland cement mortar samples are described in the following subsections. The treatment processes to obtain standard sand and the treated coal bottom ash are also provided.

\subsection{Cement}

A Type I Portland cement (PC) which complied with the requirements of ASTM C150 was used as the main binder, with a specific surface area of $320 \mathrm{~m}^{2} / \mathrm{kg}$ and a specific gravity of 3.1 . The chemical compositions of the Type I Portland Cement include $\mathrm{Al}_{2} \mathrm{O}_{3}(5.27 \%), \mathrm{Fe}_{2} \mathrm{O}_{3}(3.1 \%), \mathrm{CaO}(62.8 \%), \mathrm{MgO}(1.52 \%), \mathrm{SO}_{3}(2.73 \%), \mathrm{Na}_{2} \mathrm{O}(0.16 \%)$ and $\mathrm{K}_{2} \mathrm{O}(0.63 \%)$ [8]. Fuel Inlet: At the fuel inlet boundary, velocity profile of the fuel jet is specified. Fully developed velocity profile is prescribed such that the flow rate corresponding to the experimental value is obtained. This velocity is calculated for corresponding strain rate. A constant temperature of $298 \mathrm{~K}$ is prescribed. Mass fraction value of fuel is prescribed corresponding to the experimental conditions.

\subsection{Coal Bottom Ash}

The coal bottom ash (CBA) used in the research was obtained from coal-fired Sultan Azlan Shah/ Manjung Power Plant in Perak, Malaysia. The as-received CBA particles were relatively coarse and have angular particles with very porous surface texture. The particle sizes range from as coarse as a fine gravel to a fine sand $(<10 \mathrm{~mm}$ to $75 \mu \mathrm{m})$. The CBA was first dried in an oven at $105 \pm 5^{\circ} \mathrm{C}$ and then sieved through a $300 \mu \mathrm{m}$ sieve to remove coarser particle. Subsequently the CBA was ground using a laboratory scale ball mill for 8 hours to obtain finer particle size; sufficient grinding can improve the pozzolanic activity of the bottom ash [7]. Similar approaches were earlier used to improve the reactivity of palm oil fuel ash for use as supplementary cementitious materials in engineered cementitious composites [8], high strength concrete [9], [10] and alkali activated binder [11]-[13]. In order to remove excessive unburned carbon which will affect the potential pozzolanic properties, the $\mathrm{CBA}$ was heated at $550 \pm 50^{\circ} \mathrm{C}$ for 60 min in an electric furnace [14]. Then, the heat treated CBA was subjected to further grinding for 12 hours using the same laboratory ball mill to obtain finer particles of CBA. The chemical compositions of the CBA determined by using X-ray fluorescence spectrometer include $\mathrm{SiO}_{2}(34.09 \%), \mathrm{Al}_{2} \mathrm{O}_{3}$ (9.31\%), $\mathrm{Fe}_{2} \mathrm{O}_{3}(12.39 \%), \mathrm{CaO}$ (11.88\%), $\mathrm{MgO}(5.28 \%), \mathrm{SO}_{3}(0.91 \%)$, $\mathrm{Na}_{2} \mathrm{O}(0.12 \%), \mathrm{K}_{2} \mathrm{O}(0.51 \%)$ and $1.84 \%$ loss on ignition [15]. Based on ASTM C618, the coal bottom ash in this study could be classified as Class $\mathrm{C}$ mineral admixture. The specific surface area and specific gravity of the treated CBA were $316 \mathrm{~m}^{2} / \mathrm{kg}$ and 2.9 , respectively. It was used as a supplementary binder, replacing part of the Portland cement up to a replacement level of $30 \%$.

\subsection{Fine Aggregate}

Mining sand complying with ASTM C778 [16] was used as fine aggregate in the mortar mixtures. In order to remove the excessive silt, the mining sand was wet-sieved and materials passing 75 micron sieve which are classified as silt were removed. Subsequently, the mining sand was oven dried at $105 \pm 5^{\circ} \mathrm{C}$ for $24 \pm 0.5$ hours. The evaluated physical characteristics of the mining sand, include a fineness modulus of 2.9 , specific gravity of 2.6 and water absorption of $1 \%$.

\subsection{Mix Proportions and Samples Preparation}

The material compositions of the mortar mixes prepared and tested in this study are shown in Table 1 . A total of 8 batches of mortar mixtures with cement: sand ratio of 1:2.5 and 1:2.75 each with water/binder ratio of 0.58 and 0.64 , respectively were prepared. Mortar mixtures containing CBA were proportioned to have CBA content of 10, 20 and $30 \%$ replacing the Portland cement on-mass-for mass basis. The reference mixtures used only Portland cement (CEM 
1) as the binder. Hence, the mortar mixtures were given designations of $A_{\text {Ref }}, A_{10}, A_{20}$ and $A_{30}$ as well as $B_{R e f}, B_{10}, B_{20}$ and $\mathrm{B}_{30}$ for binder: sand ratio of $1: 2.5$ and 1:2.75, respectively.

Mortar mixtures as detailed in Table 1 were prepared for determination of compressive strength, porosity, water absorption and gas permeability. Prior to casting the samples, the flow of the fresh mortars were evaluated. Subsequently, fithteen pieces of $50 \mathrm{~mm}$ cube specimens for compression testing were made for each mixture. In addition, eight pieces of $50 \mathrm{~mm}$ cube specimens were prepared for porosity and water absorption testing. Meanwhile eight pieces of mortar cylindrical specimens having a diameter of $50 \mathrm{~mm}$ and a thickness of $40 \mathrm{~mm}$ were made for gas permeability testing. The samples were demoulded $24 \mathrm{~h}$ after casting and properly kept on the shelves of the moist room maintained at $20^{\circ} \mathrm{C}$ with $90 \%$ humidity and cured until they were required for testing. The samples were tested for compressive strength, water absorption, porosity and gas permeability after 3, 7, 28, 56 and 90 days of curing.

Table 1 - Mix compositions and fresh properties of mortars

\begin{tabular}{ccccccccc}
\hline $\begin{array}{c}\text { Mortar } \\
\text { Mix }\end{array}$ & $\begin{array}{c}\text { Cement: } \\
\text { fine agg. } \\
\text { ratio }\end{array}$ & $\begin{array}{c}\text { Portland } \\
\text { cement } \\
\left(\mathbf{k g} / \mathbf{m}^{\mathbf{3}}\right)\end{array}$ & $\begin{array}{c}\text { Treated } \\
\mathbf{C B A} \\
\left(\mathbf{k g} / \mathbf{m}^{\mathbf{3}}\right)\end{array}$ & $\begin{array}{c}\text { Fine } \\
\text { aggregate } \\
\left(\mathbf{k g} / \mathbf{m}^{\mathbf{3}}\right)\end{array}$ & $\begin{array}{c}\text { Water } \\
\left(\mathbf{k g} / \mathbf{m}^{\mathbf{3}}\right)\end{array}$ & $\begin{array}{c}\text { Water/ } \\
\text { binder } \\
\text { ratio }\end{array}$ & $\begin{array}{c}\text { Water/ } \\
\text { cement } \\
\text { ratio }\end{array}$ & $\begin{array}{c}\text { Flow } \\
(\boldsymbol{\%})\end{array}$ \\
\hline $\mathrm{A}_{\mathrm{Ref}}$ & $1: 2.50$ & 625.0 & 0.0 & 1562 & 363 & 0.58 & 0.58 & 67 \\
$\mathrm{~A}_{10}$ & $1: 2.50$ & 562.5 & 62.5 & 1562 & 363 & 0.58 & 0.65 & 57 \\
$\mathrm{~A}_{20}$ & $1: 2.50$ & 500.0 & 125.0 & 1562 & 363 & 0.58 & 0.73 & 47 \\
$\mathrm{~A}_{30}$ & $1: 2.50$ & 437.5 & 187.5 & 1562 & 363 & 0.58 & 0.83 & 40 \\
\hline $\mathrm{B}_{\mathrm{Ref}}$ & $1: 2.75$ & 592.0 & 0.0 & 1628 & 379 & 0.64 & 0.64 & 65 \\
$\mathrm{~B}_{10}$ & $1: 2.75$ & 532.8 & 59.2 & 1628 & 379 & 0.64 & 0.71 & 51 \\
$\mathrm{~B}_{20}$ & $1: 2.75$ & 473.6 & 118.4 & 1628 & 379 & 0.64 & 0.80 & 45 \\
$\mathrm{~B}_{30}$ & $1: 2.75$ & 414.4 & 177.6 & 1628 & 379 & 0.64 & 0.91 & 31 \\
\hline
\end{tabular}

\subsection{Test Procedures}

\subsubsection{Flow of Mortar}

The flow of the fresh cement mortar was measured by means of the flow of cement mortar test in accordance to ASTM C1437 [17]. This test method is used for the determination of the flow of hydraulic cement mortar, and of mortars containing cementitious materials other than hydraulic cements. It is commonly used as a standard test when there is a requirement for a mortar to have a water content that provides a specified flow level. An adequate flow of cement mortar is needed so that the mortar can be placed and compacted to maximum density [6].

\subsubsection{Compressive Strength of Mortar}

The compressive strength of mortar is defined as the maximum compressive stress that it can support before failure. The standard method described in ASTM C109 [18], Compressive Strength of Hydraulic Cement Mortars was followed for the compressive strength test. Three pieces of mortar cube specimens were tested at each testing age for each mixture and the average strength was reported.

\subsubsection{Porosity and Water Absorption}

In this study, the porosity and water absorption were determined following the water immersion under vacuum method prescribed by RILEM (1984) [19]. Firstly, the mortar samples were oven dried in a ventilated oven at $105 \pm$ $5^{\circ} \mathrm{C}$ for $24 \pm 0.5$ hours and then the oven dried mass $\left(\mathrm{W}_{4}\right)$ of the samples was determined. Next, the samples were placed in the vacuum saturation apparatus and a vacuum pressure of one bar was applied for three hours. While the specimens were still under vacuum, deionized water was introduced so as to submerge the specimens until about 10 $\mathrm{mm}$ of water covering the topmost surface of the specimens. This process was continued by maintaining the vacuum pressure for three hours after an introduction of water. Then, the pressure was released and the specimens were kept submerged in water for another one hour to achieve full saturation. Lastly, the specimens were removed from the water, their surfaces were wiped with a dry cloth and subsequently their mass in air $\left(\mathrm{W}_{2}\right)$ and in water $\left(\mathrm{W}_{3}\right)$ were determined.

The porosity (P) was computed by using Eq. (1), whilst the water absorption (A) was calculated by using Eq. (2).

$$
\begin{aligned}
& P(\%)=\left(\frac{W_{2}-W_{4}}{W_{2}-W_{3}}\right) \times 100 \\
& A(\%)=\left(\frac{W_{2}-W_{4}}{W_{4}}\right) \times 100
\end{aligned}
$$


The flow of the fresh cement mortar was measured by means of the flow of cement mortar test in accordance to ASTM C1437 [17]. This test method is used for the determination of the flow of hydraulic cement mortar, and of mortars.

\subsubsection{Gas Permeability}

Permeability is one of the main parameters influencing the durability performance of cement based materials including concrete and mortar. The assessment of gas permeability of mortar was undertaken using a gas permeameter similar to that developed by Cabrera and Lynsdale [20] but utilizing a nitrogen gas. The coefficients of gas permeability of the mortar samples were computed using Equation 3, which is based on Darcy's equation [21].

$$
K=2 . \eta \cdot \frac{L}{A} \cdot \frac{V}{t} \cdot \frac{P_{2}}{P_{1}^{2}-P_{2}^{2}}
$$

where: $K=$ specific gas permeability coefficient $\left(\mathrm{m}^{2}\right), \eta=$ viscosity of nitrogen gas at room temperature $\left(17.8 \times 10^{-6}\right.$ $\left.\mathrm{Ns} / \mathrm{m}^{2}\right), V=$ volume of gas passed through the concrete surface during the testing time $\left[\mathrm{m}^{3}\right], A=$ cross-sectional area in the flow direction $\left(\mathrm{m}^{2}\right), L=$ length of flow $(\mathrm{m}), P_{2}=$ atmospheric pressure, usually 1 bar, $P_{1}=$ average overpressure, $\left(P_{s}+P_{f}\right) / 2$ (bar), $t=$ time $(\mathrm{sec})$.

The volume of gas passed through the concrete or mortar surface, $\mathrm{V}$, during the testing time interval was obtained using Eq. (4):

$$
V=\frac{\left(P_{s}-P_{f}\right) V_{r e s}}{P_{a t m}}
$$

where: $P_{s}=$ absolute starting pressure (bar), $P_{f}=$ absolute final pressure (bar), $V_{\text {res }}=$ volume of the nitrogen gas reservoir, $P_{\text {atm }}=P_{2}=$ atmospheric pressure $(1 \mathrm{bar})$.

\section{Results and Discussion}

\subsection{Effect of CBA on Flow of Fresh Mortar}

The flow of both series of the mortar mixtures with cement: sand ratio of 1:2.5 and 1:2.75 is reported in Table 1. The results generally show that the inclusion of the CBA tend to reduce the workability of the resulting mortars, with greater reduction in flow at higher CBA contents. The reduction in flow of the mixtures containing CBA in comparison to the reference mortar mixtures is clearly portrayed in Fig. 1. This clearly indicates that the use of the CBA as a partial replacement of PC increases the water demand of the mortar mixtures which could be attributed to the porous surface texture of the CBA particles. In addition, the lower specific gravity of the CBA in comparison to PC implicates a higher volume of binder as a result of the mass-for-mass replacement of the PC with the CBA for the mortar mixtures containing CBA, thus contributes towards increasing the water requirement of the mortars. Since the same amount of water was used for all mixtures in the same mortar groups, the mixtures containing CBA exhibited clear reduction in the measured flow values. Therefore, the observed effect of CBA on flow and water demand of Portland cement mortar is the opposite of the effect of fly ash which has been known to reduce the water demand and increase the workability of mortar and concrete from the ball-bearing effect induced by the fly ash [22]. The porous surface and irregular shape of CBA particles are different from that of fly ash particles which are having smooth and glassy surface with spherical shape. Nonetheless, despite the fact that the CBA mortar mixes exhibited a significantly lower degree of workability in comparison to the reference mixes, compaction of the mortars was done without any problem, even with the mixes with $30 \%$ CBA content. Thus, the reduction in flow with the use of CBA should not affect the hardened properties of the mortars [23].

\subsection{Effect of CBA on Compressive Strength}

The results of the compressive strength tests on mortar mixtures containing CBA as a partial substitute of Portland cement and the reference mixtures are shown in Fig. 2 and Fig. 3. It is evident that the compressive strength increased gradually with curing time for all mortar mixtures as a result of the cement hydration in the case of the reference PC mortar mixtures and combination of Portland cement hydration as well as pozzolanic reaction for the case of the mortar mixtures containing CBA. In the first 7 days, the reference mixture showed the highest compressive strength for both series of 1:2.5 and 1:2.75 mortar mixtures, while the mortar mixtures containing CBA exhibited lower strength in particular at the higher CBA content. The reduction in strength for the mixtures containing CBA could be mainly attributed to the combined influence of a dilution effect resulting from the reduction in PC content and the relatively slower pozzolanic reactivity as well as delay onset of pozzolanic reaction of the CBA [24]. The lower the cement 
content as a result of the inclusion of greater amount of CBA led to greater dilution effect, hence lowered the strength of the mortars at early ages. Nonetheless, for the mortar mixtures with 1:2.5 cement: sand ratio containing 10 and $20 \%$ $\mathrm{CBA}$, there is a clear trend that the compressive strength was higher than that of the reference mixture at longer curing periods of 28, 56 and 90 days, with the $A_{10}$ mixture exhibiting the highest strength at the stated curing periods. In the case of the mixture containing $30 \% \mathrm{CBA}\left(\mathrm{A}_{30}\right)$, its strength was the lowest at all curing periods. The higher increase in strength than the reference mixture at longer curing periods for the mixtures containing 10 and $20 \%$ CBA could be due to the pozzolanic reaction to sustain the pozzolanic reaction of the CBA at the longer curing periods to produce secondary C-S-H, thus promoting higher strength. However, at much higher CBA content of $30 \%$, the dilution effect from the significant reduction in cement content and the higher CBA content could have been more dominant. Hence, less $\mathrm{C}-\mathrm{S}-\mathrm{H}$ as well as less $\mathrm{Ca}(\mathrm{OH})_{2}$ could have been produced from the PC hydration reaction, consequently limiting the probable pozzolanic reaction of the CBA and ultimately leading towards lower strength.

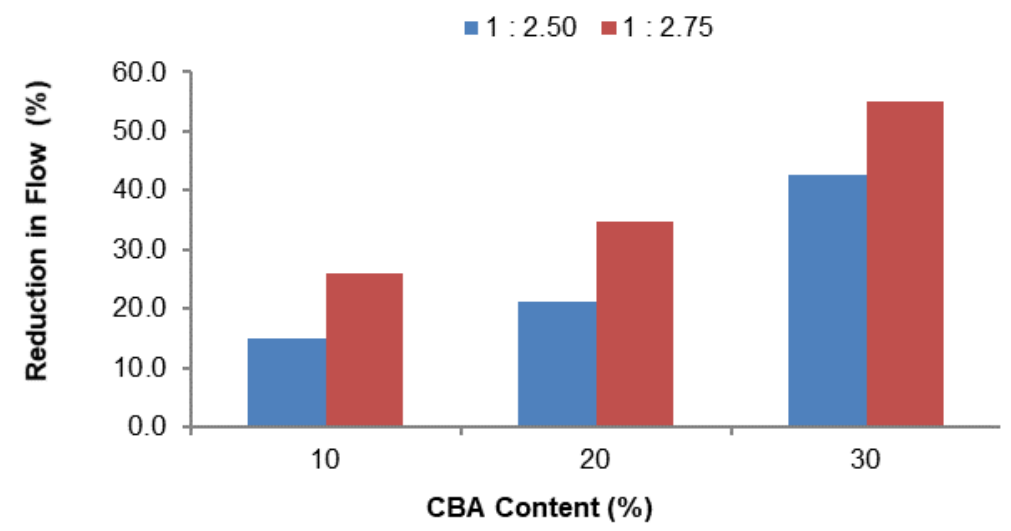

Fig. 1 - Reduction in flow of mortar mixtures containing CBA

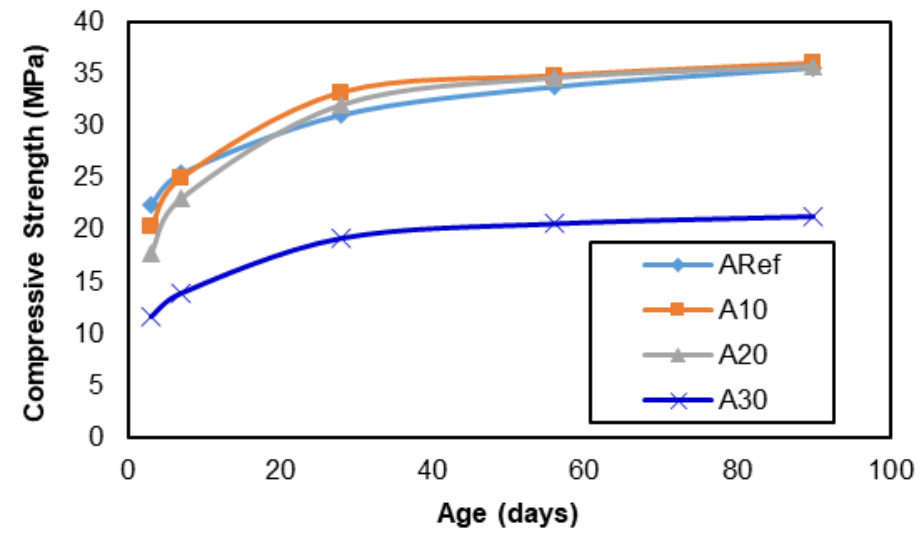

Fig. 2 - Effect of CBA on compressive strength of mortar (Cement: sand ratio of 1:2.5)

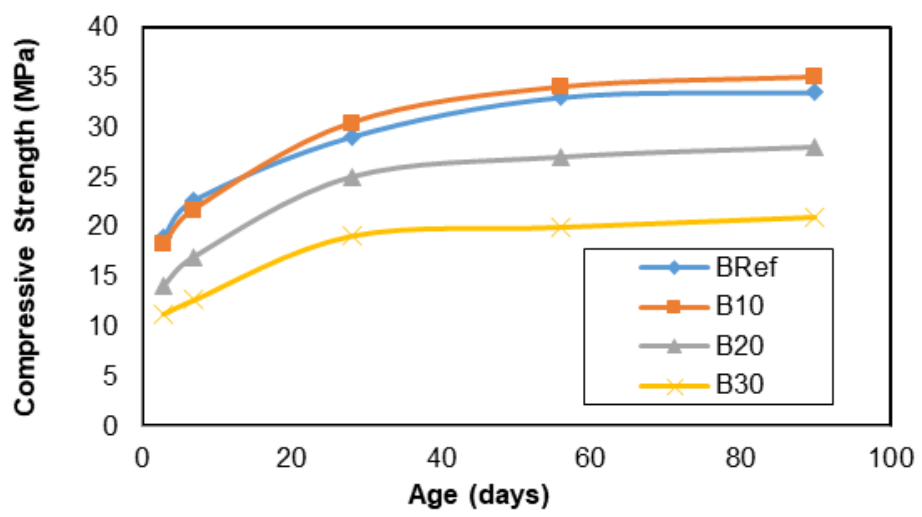

Fig. 3 - Effect of CBA on compressive strength of mortar (Cement: sand ratio of 1:2.75) 
In the case of the mortar mixtures with cement: sand ratio of 1:2.75, their strength is generally lower than their counterparts with cement: sand ratio of 1:2.5. This trend is attributed to the higher water/binder ratio and lower binder content of the mortars with cement: sand ratio of 1:2.75. Furthermore, in comparison to the reference mixture, the enhancement in strength at the longer curing periods of 28, 56 and 90 days as a result of the CBA inclusion was only observed at CBA content of $10 \%$. At higher CBA content of 20 and $30 \%$, the strength of the mortars appeared to reduce with greater reduction in strength at the higher CBA content. Again, this different trend could have been influenced by the higher water/binder ratio and lower binder content of the mortar mixture with cement: sand ratio of 1:2.75, exacerbating the dilution effect as the binder particles are pushed further apart and creating more pores to be filled by the products of hydration and pozzolanic reaction, thus leading to lower strength. From the overall results, it seems that the optimum CBA content for both series of mortar mixtures in order to obtain maximum strength at 28 days and beyond is $10 \%$. The reactivity of the CBA could probably be improved by further refining the particle size of the CBA to increase its specific surface area [25] which could provide better effect on compressive strength.

\subsection{Effect of CBA on Porosity and Water Absorption}

The porosity of the cement mortars with different cement: sand ratios and having different CBA content is shown in Fig. 4 and Fig. 5 for mortar mixtures with cement: sand ratios of 1:2.5 and 1:2.75, respectively. While the results for water absorption are shown in Fig. 6 and Fig. 7 for mortar mixtures with cement: sand ratios of 1:2.5 and 1:2.75, respectively. In general, the results show that both the porosity and water absorption of both series of mortars reduced with curing time, but the reduction after 28 days is rather negligible. From 3 to 28 days, there seems to be quite a significant reduction in porosity and water absorption which could be attributed to the hydration of cement and hydration of cement complimented with pozzolanic reaction of CBA in the case of mortar mixtures containing CBA, producing $\mathrm{C}-\mathrm{S}-\mathrm{H}$, filling the pores and leading to the overall reduction in porosity and water absorption. However, from the age of 28 to 90 days both the porosity and water absorption underwent very marginal reduction. Comparison between the different mixtures indicates that for both series of mortar mixtures, the reference mixtures exhibited lower value of porosity and water absorption at the early ages of 3 and 7 days, while the effect of CBA inclusion was to increase both the porosity and water absorption, with greater increase at the higher CBA content. This observed trend could be explained as due to the dilution effect resulting from the reduction in cement content as well as the slower rate of pozzolanic reaction of the CBA. Nonetheless, at longer curing periods of 28 days up to 90 days, there is a clear trend that the mixtures containing 10 and $20 \%$ CBA portrayed lower porosity and water absorption than the reference mixture for the 1:2.5 mortar, and mixture with 10\% CBA for the case of the 1:2.75 mortar. The reduction in porosity as well as water absorption could be associated with the pozzolanic reaction of the CBA, but both porosity and water absorption increased at higher CBA content due to the more dominant dilution effect as a result of lower cement content. Furthermore, the mortar mixtures with cement:sand ratio of 1:2.5 seem to generally register lower porosity and water absorption than their counterparts with cement:sand ratio of 1:2.75 due to the higher binder content and lower water/binder ratio of the mortar mixtures with cement:sand ratio of 1:2.5.

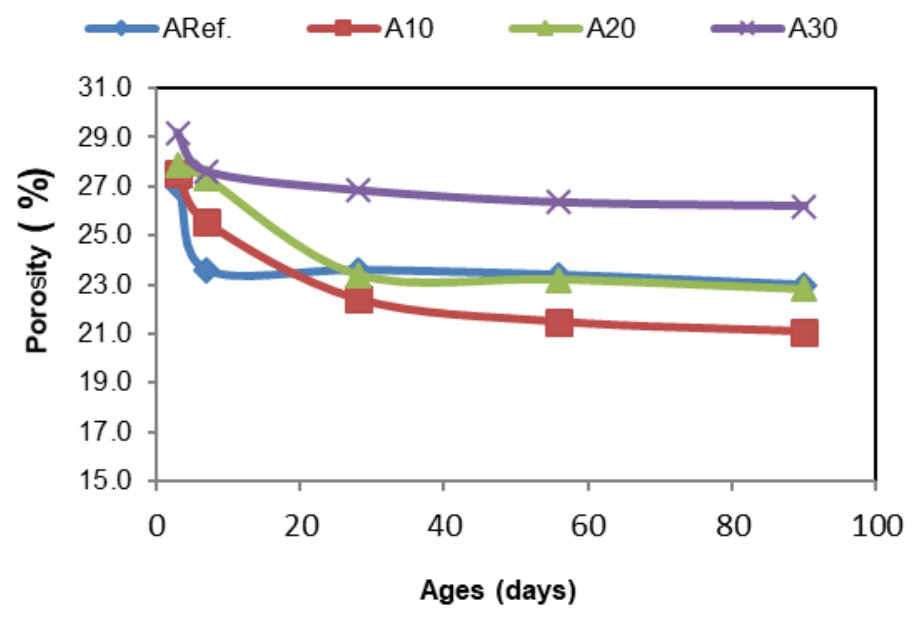

Fig. 4 - Effect of CBA on porosity of mortar (cement: sand ratio of 1:2.5) 


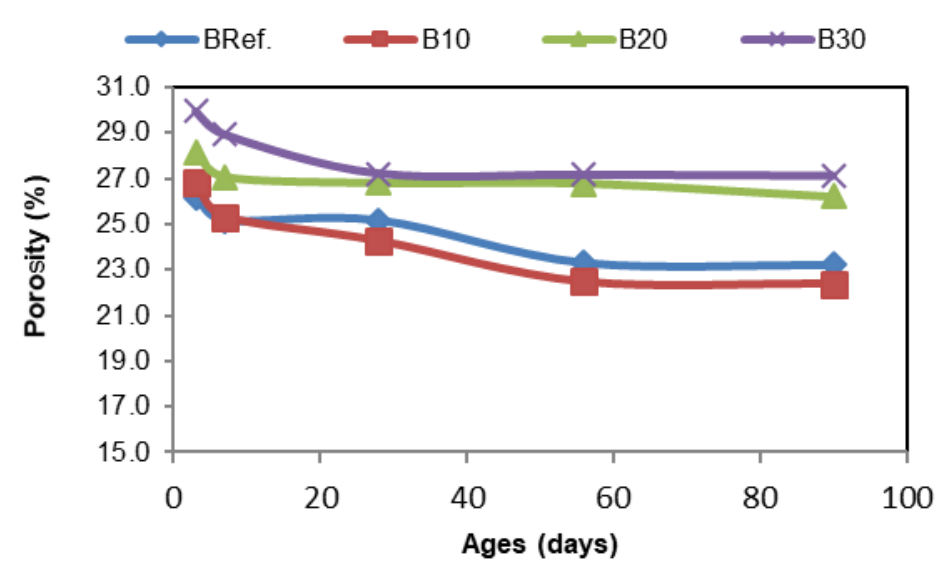

Fig. 5 - Effect of CBA on porosity of mortar (cement:sand ratio of 1:2.75)

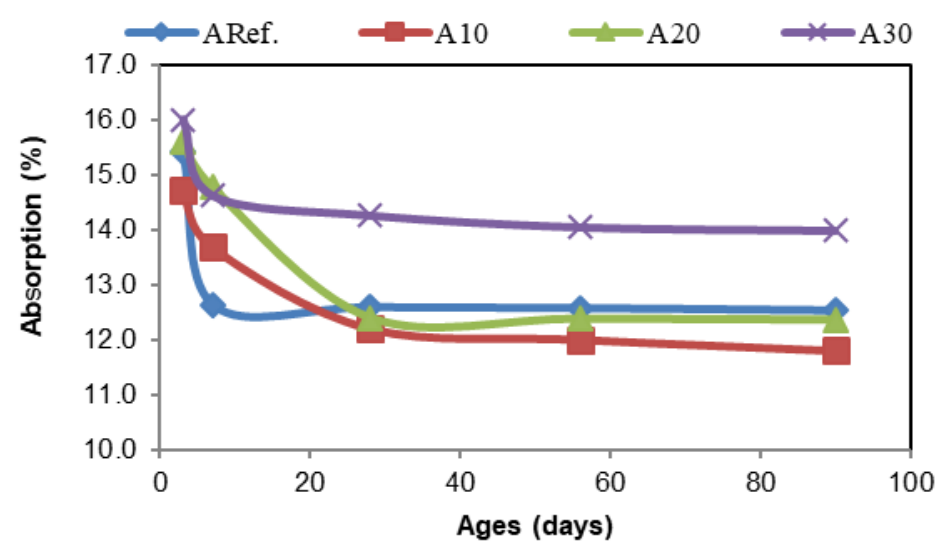

Fig. 6 - Effect of CBA on water absorption of mortar (Cement: sand ratio of 1:2.5)

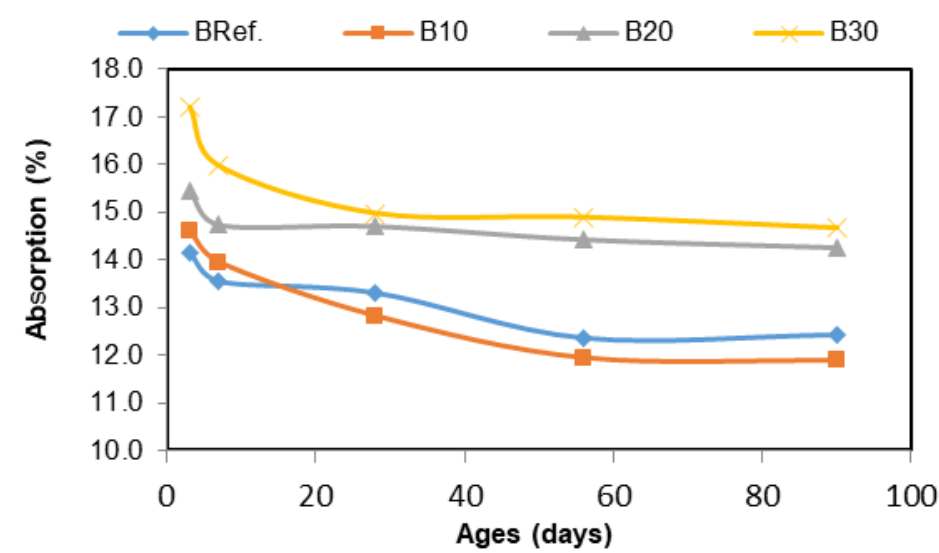

Fig. 7 - Effect of CBA on water absorption of mortar (cement:sand ratio of 1:2.75)

\subsection{Effect of CBA on Gas Permeability}

The coefficient of gas permeability of the mortar mixtures is shown in Fig. 8 and Fig. 9 for mixtures with cement:sand ratio of 1:2.5 and 1:2.75, respectively. In general, there is a clear trend that the coefficient of gas permeability reduces with curing times from 3 to 90 days. This reduction could be attributed to the hydration of cement in the case of the reference mixtures as well as hydration of cement complimented with pozzolanic reaction of the CBA for the case of the mortar mixtures containing CBA. With longer curing time, the hydration and pozzolanic reaction further progressed producing greater amount of $\mathrm{C}-\mathrm{S}-\mathrm{H}$, segmenting and refining the pores and leading to lower permeability. As in the case of porosity and water absorption, the effect of CBA is to increase the coefficient of permeability at the early ages but tends to reduce the coefficient of permeability at longer curing period. This is true for 
the mixtures containing 10 and 20\% CBA for the 1:2.5 mixture and 10\% CBA for the 1:2.75 mixture. At higher CBA content, the reduction in the Portland cement content leads to slightly higher coefficient of permeability. From the overall results, it seems that lower long-term permeability could be achieved with the use of 10\% CBA.

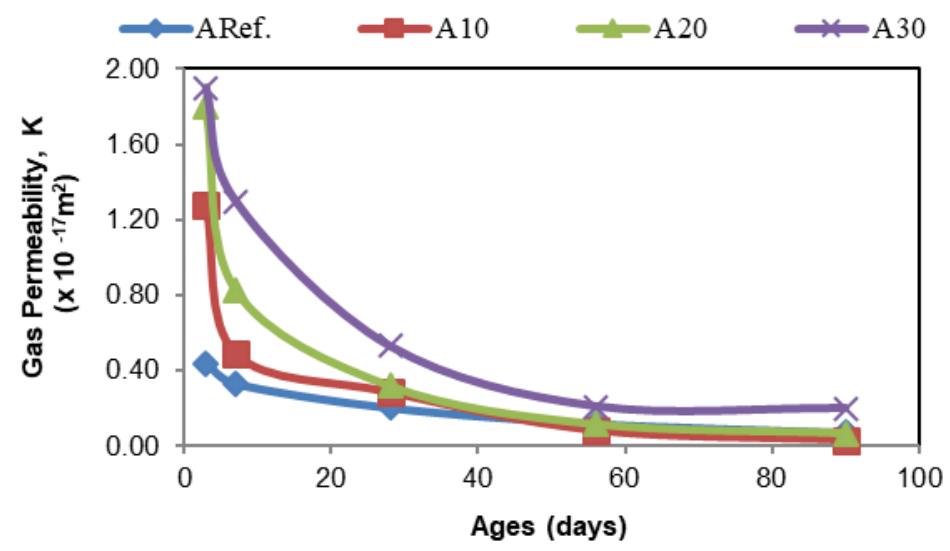

Fig. 8 - Effect of coal bottom ash on gas permeability coefficient (cement:sand ratio of 1:2.5)

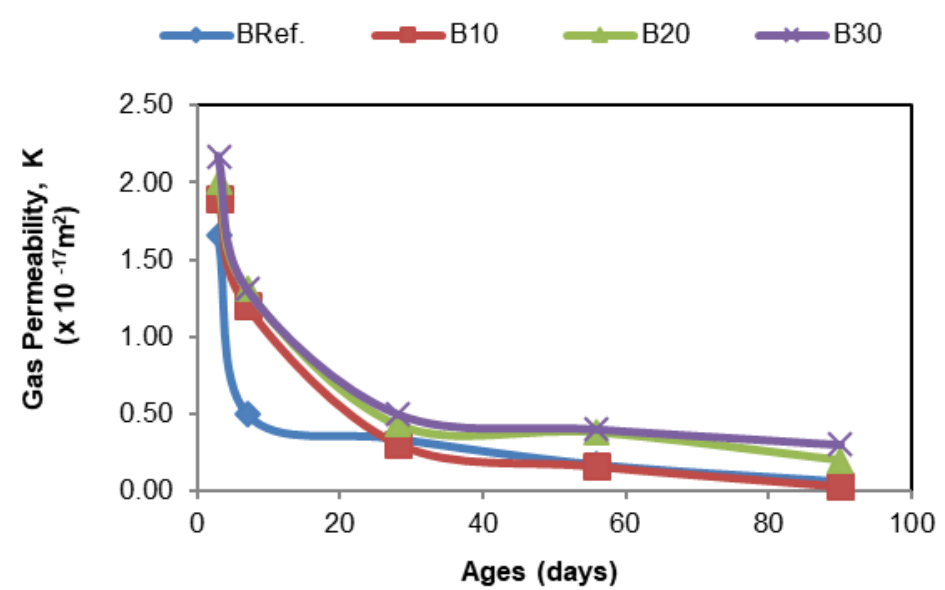

Fig. 9 - Effect of coal bottom ash on gas permeability coefficient (cement: sand ratio of 1:2.75)

\section{Conclusions}

This study investigated the probability of using CBA as a partial Portland cement replacement material in the production of mortar. Based on the results presented earlier as well as the corresponding discussion, the following conclusions can be drawn;

i) The inclusion of $\mathrm{CBA}$ as partial replacement of Portland cement increases the water demand of the mortar mixtures leading to reduction in the flow of the mortars, with lower flow at higher CBA contents.

ii) The CBA can effectively replace Portland cement up to $20 \%$ of the 1:2.5 and 10\% of the 1:2.75 mortar mixtures, with marginal strength improvement at the ages of 28, 56 and 90 days. The results approve that the CBA has some pozzolanic reactivity leading to small increase in strength at low replacement level and longer curing periods in the CBA mortars in comparison to the control mixtures.

iii) The effects of CBA inclusion is to reduce the porosity, water absorption and permeability of the Portland cement mortars at longer curing period of 28, 56 and 90 days for CBA contents of 10 and 20\% in the 1:2.5 mortar mixtures, and for CBA content of $10 \%$ in the 1:2.75 mortar mixtures.

\section{Acknowledgements}

The authors gratefully acknowledge the research grant supported by Universiti Sains Malaysia under project, A/C: 304/PAWAM/60313001. 


\section{References}

[1] Abubakar, A. U. and Baharudin, K. S. (2012) Potential use of malaysian thermal power plants coal bottom ash in construction. International Journal of Sustainable Construction Engineering and Technology, 3, 25-37.

[2] Tsen, M. Z. (2008). The properties of fly ash-based geopolymer mortar with potassium based alkaline reactor, BEng Thesis. Curtain University of Technology.

[3] Marto, A., Kassim, K. A., Makhtar, A. M., Wei, L. F. and Lim, Y. S. (2010). Engineering characteristics of Tanjung Bin coal ash. Electronic Journal of Geotechnical Engineering, 15, 1117-1129.

[4] Manz, O. E. (1997). Worldwide production of coal ash and utilization in concrete and others Products. Fuel, 76(8), 691-696.

[5] Cheriaf, M., Calvalcante, R. J. and Pera, J. (1999). Pozzolanic properties of pulverized coal combustion bottom ash. Cement and Concrete Research, 29, 1387-1391.

[6] Kurama, H. and Kaya, M. (2008). Usage of coal combustion bottom ash in concrete mixture. Construction Building Material, 22, 1922-1928.

[7] Kula, I., Olgun, A., Y. Erdogan, Y. and Sevin, V. (2001). Effects of colemanite waste, cool bottom ash, and fly ash on the properties of cement. Cement and Concrete Research, 31, 491-494.

[8] Altwair, N. M., Megat Johari, M. A. and Saiyid Hashim, S. F. (2014). Influence of treated palm oil fuel ash on compressive properties and chloride resistance of engineered cementitious composites. Materials and Structures, 47, 667-682.

[9] Megat Johari, M. A., Zeyad, A. M., Muhamad Bunnori, N. and Ariffin, K. S. (2012). Engineering and transport properties of high-strength green concrete containing high volume of ultra-fine palm oil fuel ash. Construction and Building Material, 30, 281-288.

[10] Mohammed, A. N., Megat Johari, M. A., Zeyad, A. M., Tayeh, B. A. and Yusuf, M. O. (2014). Improving the engineering and fluid transport properties of ultra-high strength concrete utilizing ultrafine palm oil fuel ash. Journal of Advanced Concrete Technology, 12, 127-137.

[11] Yusuf, M. O., Johari, M. A. M., Ahmad, Z. A. and Maslehuddin, M. (2014). Evolution of alkaline activated ground blast furnace slag- ultrafine palm oil fuel ash based concrete. Materials and Design, 55, 387-393.

[12] Mijarsh, M. J. A., Megat Johari, M. A. and Ahmad, Z. A. (2014). Synthesis of geopolymer from large amount of palm oil fuel ash - Application of the Taguchi method in investigating the main parameters affecting compressive strength. Construction and Building Materials, 52, 473-481.

[13] Yusuf, M. O., Megat Johari, M. A., Ahmad, Z. A. and Maslehuddin, M. (2014). Strength and microstructure of alkali-activated binary blended binder containing palm oil fuel ash and ground blast-furnace slag. Construction and Building Materials, 52, 504-510.

[14] Ibrahim, A. H., Choong, K. K., Johari, M. A. M., Rosli, R. N. and Ariffin, K. S. (2015). Effects of coal bottom ash on the compressive strength of Portland cement mortar. Applied Mechanics and Materials, 802, 149-154.

[15] Ibrahim, A. H., Choong, K. K., Johari, M. A. M., Rosli, R. N. and Ariffin, K. S. (2015). Comparative study on chemical composition of coal ash amongs Malaysian coal-fired power plants. Malaysian Construction Research Journal, 17(2), 69-78.

[16] American Society for Testing and Materials (2003). Standard specification for standard sand. Pennsylvania: ASTM C778.

[17] ASTM International (2007). Standard test method for flow of hydraulic cement mortar. Pennsylvania: ASTM C1437.

[18] ASTM International (2013). Standard test method for compressive strength of hydraulic cement mortars (using 2in. or [50-mm] cube specimens). West Conshohocken: ASTM C109/ C109M.

[19] RILEM (1984). Absorption of water by immersion under vacuum. Materials and Structures, 17(101), $391-394$.

[20] Cabrera, J. G. and Lynsdale, C. J. (1988). A new gas permeameter for measuring the permeability of martar and concrete. Magazine of concrete research, 40(144), 177-182.

[21] Dinku, A. and Reinhardt, H. W. (1997). Gas permeability coefficient of cover concrete as a performance control. Materials and Structures, 30, 387-393.

[22] Megat Johari, M. A., Brooks, J. J., Kabir, S. and Rivard, P. (2011). Influence of supplementary cementitious materials on engineering properties of high strength concrete. Construction and Building Materials, 25, $2639-2648$.

[23] Barbhuiya, S. A., Gbagbo, J. K., Russell, M. I. and Basheer, P. A. M. (2009). Properties of fly ash concrete modified with hydrated lime and silica fume. Construction and Building Materials, 23, 3233-3239.

[24] Canpolat, F., Y1lmazb, K., Ko“"se, M. M., Su“merb, M. and Yurdusev, M. A. (2004). Use of zeolite, coal bottom ash and fly ash as replacement materials in cement production. Cement and Concrete Research, 34, 731-735.

[25] Sheng, G., Li, Q., Zhai, J. and Li, F. (2007). Self-cementitious properties of fly ashes from CFBC boilers co-firing coal and high-sulphur petroleum coke. Cement and Concrete Research, 37, 871-876. 